\title{
Application of AHP to Multi-Item Inventory Management Using Part Period Algorithm
}

\author{
Hossein Jamshidi \\ Professor of Operations Management, Department of Management, Marketing and \\ Logistics \\ College of Business and Public Affairs, Alabama A\&M University \\ E-mail: Hossein.jamshidi@aamu.edu
}

Emeka Dunu

Professor of Management Science, Department of Management, Marketing and Logistics

College of Business and Public Affairs, Alabama A\&M University

E-mail: emeka.dunu@aamu.edu

Guy Posey

Professor of Management Information Systems, Department of Management, Marketing and Logistics

College of Business and Public Affairs, Alabama A\&M University

E-mail: guy.posey@aamu.edu

Received: Feb. 25, $2020 \quad$ Accepted: July 1, $2021 \quad$ Published: July 1, 2021

doi:10.5296/jmr.v13i3.18347 URL: https://doi.org/10.5296/jmr.v13i3.18347

\begin{abstract}
This empirical study deals with integration of Analytical Hierarchy Process (AHP) with multi-item inventory management using Part-Period Algorithm. Among many variables which affects inventory systems, this study considers the variables of lot-sizing rules, sequencing, demand pattern, coefficient of variations, and change over cost. AHP is used to pick a sequencing rule and performance criteria. This study describes the application of AHP methodology in the form of multiple tables that will assist production managers in a Group Technology environment, to minimize employee and machine idleness. It will help
\end{abstract}


managers make decisions on production order quantity, the sequence in which jobs should enter work centers, and in the determination of uniform production cycle times.

Keywords: AHP, Inventory Management, Decision Making, Part Period Algorithm, Group Technology. 


\section{Introduction}

2021, Vol. 13, No. 3

According to Decision Support System Resources (Powers, 2021), Analytical Hierarchy Process (AHP) is defined as "an approach to decision making that involves structuring multiple choice criteria into a hierarchy, assessing the relative importance of these criteria, comparing alternatives for each criterion, and determining an overall ranking of the alternatives", AHP provides a recognized effective approach to deal with complex decision making by organizing and assessing alternatives against a hierarchy of multifaceted objectives. It tremendously reduces the decision-making cycle, and helps capture both subjective and objective evaluation measures (Parcom, 2007). It also provides a useful mechanism for checking the consistency of the evaluation measures and alternatives suggested by the decision-making. Saaty (1980), the developer of AHP, claims that AHP is "natural to our intuition and general thinking," which combines logic and intuition and takes advantage of our ability to rank choices. Group Technology (GT) is described as a manufacturing philosophy in which similar parts are identified and grouped to take advantage of their similarities in design and manufacturing to eliminate waste in process and inventory, improve utilization of work centers and workforce, increase productivity and efficiency, gain competitive advantage and improve customers' satisfaction (Denny, 2021). After groups are formed in a GT environment, three associated questions to be answered are:

(1) What is the priority ranking of each part or job within each group?

(2) What portion of the forecasted demand should be produced in each run over a given planning horizon (for each part in a group)?

(3) What should be the uniform cycles of production time?

These questions are addressed by the integration of sequencing, scheduling, and uniform cycles of production time. Sequencing is concerned with allocation of jobs, orders, or activities to machine operations or resources in order to optimize performance criteria. Scheduling refers to decisions about timing and quantity of products to be produced. A production cycle time is the time required to restart production of a product. A uniform production cycle time for several products is the time during which those products will be ready for reproduction.

A production cycle for an order of size $Q_{i}$ for $i=1$ to $n$ jobs, will cover a fixed number of

planning periods. In this empirical study, AHP is applied to decide which sequencing rule to use and integrate the sequencing rule with scheduling and subsequent formation of cycle of production within a group technology environment. Integration of sequencing and scheduling with GT and development of production cycles would provide managers tools in making decision on order quantity and utilization of work centers. In this research, it is assumed that groups have already been formed, and demand for each item within a group is forecast over a finite planning horizon. Specifically, the questions address in this study are: 
- What is the priority ranking of each job within each group in order to optimize performance criterion such as mean flow time?

- What quantity of each product should be processed?

- What is the length of the uniform production cycle time?

Sequencing deals with the order jobs should be processed in a work center. There are many sequencing rules for processing $\mathrm{N}$ jobs in a work center. However, this study considers the five priority rules of First Come First Served (FCFS), Shortest Processing Time (SPT), Early Due Date (EDD), critical Ratio (CR) and Slack (S) time (Stevenson, 2018). The performance of sequencing rules is measured by job flow time, job lateness or make span time. Flow time is the most commonly used method to measure the performance of a sequencing rule. 2 The flow time for a job is the sum of its waiting and processing time. This study is an effort to provide managers with tools in the form of multiple tables to assist them in deciding on order size, determine uniform production cycle time, and obtain the sequence for processing jobs within a product family in order to optimize flow time. Determination of production cycle would essentially lead to efficient utilization of work centers, minimization of employee idleness, and proper management of work centers.

Pujawan (2003) examined characteristics of lot-sizing rules under lumpy demand. 3 In his study, he presented both analytical and experimental studies of lot-sizing rules for lumpy demand situations. The analytical study assumes that constant demand occurs for every fixed number of periods. In the experimental study, both quantities of demand and time between demands are can vary. Bahl, (1987) and Brahimi, (2006) have extensively studied the classification of lot sizing problems. However, Haddock and Hubicky (1989) argue that the most commonly used lot sizing technique in industrial contexts is the simple lot-for-lot rule, followed by fixed order quantity and fixed period quantity.

Lot sizing heuristics analysis still represents an important field of research in operations research and management. Several authors have focused on classifying different solution approaches for various classes of lot sizing problems. The dynamic capacitated lot sizing problem is studied by Busckul et. al. (2010). Stochastic lot sizing problem is studied by Winands et. al. (2011), the rolling horizon lot sizing problem is studied by Tiacci and Saetta (2012) and the online lot sizing problem is discussed by Van den Heuvel (2010). For unconstrained lot sizing problem, Goren et. al. (2010) provided significant insights on specific solution techniques for genetic algorithms, and an evolutionary algorithm for solving unconstrained multi-level lot-sizing problem is discussed by Han et. al. (2012). The problem of neighborhood search techniques for solving incapacitated multilevel lot-sizing problem is addressed by Xiao (2012). Baciarello et al., (2013) used unique modelling methodology to examine eight of the topmost lot sizing algorithms that have been exhaustively tested on several different scenarios, and compared with Wagner and Whitin's optimal solution. 2 Wagner and Whitin (1958) solved the finite-period, deterministic single-item problem. Later authors have generalized the Wagner-Whitin model under different scenarios. Gelders et al. (1986) use solution method based on 
heuristics like branch-and-bound. Suerie and Stadtler (2003) use time-oriented decomposition heuristics, while Meyer (2000) use meta-heuristic like Threshold Accepting and Simulated Annealing, and Gopalakrishnan et al. (2001) use Tabu search. Clark (2003) proposes the hybrid use of local search and integer programming. Also, some authors assumed that every product is produced in equal quantities at each production point (Doll 1973, Goyal 1973, Haessler 1971 and 1976, Hodson 1970, Madigan 1968).

\section{Variables}

Integration of scheduling, sequencing, and production cycles times could result in many variables or factors influencing the problem under consideration. 2 However, the effect and importance of some variables outweigh others. The following five variables are discussed in this study and to generalize the result and finding, these variables are represented in the normalized or standardized form. 2 The variables or factors considered in this study are:

1. Demand Pattern

2. Coefficient of Variation (CV)

3. Changeover Cost

4. Lot-sizing Rules

5. Sequencing

There can be an infinite number of demand patterns. However, this study considers six different patterns namely: Increasing (I), Decreasing (D), Concave (A), Convex (V), Seasonal (S), and Random (R) pattern. Coefficient of Variation (CV) is defined as a measure of relative variation which is independent of the scale of measurement $(\mathrm{CV}=\mathrm{s} / \mathrm{x})$ (Miller 1985). The CV is used to represent the degree of fluctuations in the net requirement of a finished product (Berry 1972, Kaiman 1969, Karni 1982). Three different CVs are considered on the data generated for each of the six demand patterns listed earlier. These ratios are represented by Low (L), medium (M), and high $(\mathrm{H})$ degrees which are set respectively as $0.12,0.30$, and 0.667 .2 These ratios relatively cover a broad range of demand variations. Changeover or setup cost occurs in the continuous process industry when switching from one product to another. The major components of changeover cost are setup (Co) and holding (Ch) costs. 2 In this study, three ratios of setup cost to holding cost are considered. To generalize the results, the ratios are normalized based on the magnitude of the average demand. The three cost ratios considered are $0.75,1.50$, and 3.00 times the average demand. These ratios will cover a broad range of cost structure. Other researchers (Berry 1972, Collier 1980, Kaiman 1969, Veral 1985) have used these cost ratios in their studies of lumpiness.

Several lot-sizing techniques for determining order quantities have received attention in literature. In this paper, we use Part Period Algorithm (PPA) as the lot-sizing rule. The PPA is cost effective under conditions of known but varying demand rates (lumpy demand). This procedure does not ensure optimality but does approach optimal solution 
(Davis 1975).

\section{Methodology}

The planning period in this study is arbitrarily chosen to be 10 periods, and the total demand for each demand pattern is set to be equal to 1000. This constraint is purposely introduced to enhance numerical comparability. To generalize the results, the demand for each period will be normalized by the ratio of $(\mathrm{di} / \mathrm{D})$, where di is the demand for period $\mathrm{i}$ and $\mathrm{D}=1000$ is the total demand. Six different demand patterns are used. The forecasted demands are scattered according to Increasing, Decreasing, Concave, Convex, Seasonal, and Random patterns, which are represented by I, D, A, V, S, and R respectively.

The sequencing methods are compared and analyzed using AHP method. AHP requires respondents to rank the sequencing methods by using pair-wise comparisons and assigning a number representing weights, to each pair comparison. The numbers will be used to generate a matrix which will give the decision maker a tool to attack the larger problem.

Table 1. Pairwise Comparison of FCFS, SPT, EDD, CR and S rules Based on Average Responses

\begin{tabular}{|l|l|l|l|l|l|}
\hline & FCFS & SPT & EDD & CR & S \\
\hline FCFS & 1 & $1 / 3.44$ & 2.91 & 3.82 & 3.09 \\
\hline SPT & 3.44 & 1 & 2.11 & 4.15 & 3.51 \\
\hline EDD & $1 / 2.91$ & $1 / 2.11$ & 1 & 1.91 & 1.55 \\
\hline CR & $1 / 3.82$ & $1 / 4.15$ & $1 / 1.91$ & 1 & $1 / 2.11$ \\
\hline S & $1 / 3.09$ & $1 / 3.51$ & $1 / 1.55$ & 2.11 & 1 \\
\hline Total & $\mathbf{5 . 3 7}$ & $\mathbf{2 . 2 9}$ & $\mathbf{7 . 1 9}$ & $\mathbf{1 2 . 9 9}$ & $\mathbf{9 . 6 2}$ \\
\hline
\end{tabular}

A survey on the five sequencing rules of First Come First Served (FCFS), Shortest Processing Time (SPT), Early Due Date (EDD), critical Ratio (CR) and Slack (S) time was conducted on companies in both service and manufacturing industries in Northern Alabama and they were asked which rule is the preferable rule in their organization. The manager of each company had to do a pairwise comparison of each of the rules and rank them using a scale of 1 to 5 , indicating the degree of preference, with 1 being equally preferred, 2 being moderately preferred, 3 being strongly preferred, 4 being very strongly preferred, and 5 being extremely preferred. About 82 percentage of the service companies in the survey picked the FCFS rule as the preferred sequencing rule. However, for the manufacturing companies, there were mixed preferences. AHP results in Table 1 indicate that SPT is 2.11 times more preferred than EDD. Table 2 shows the average preference results, which are obtained by dividing each value in Table 1 by its total in that column. Table 2 shows that SPT is the most preferred rule followed by FCFS in sequencing jobs in a work center. The performance of each of the above sequencing rule could be measured by flow time (FT), job lateness (LT) or makespan time (MS). AHP is applied to find out which of these criteria is preferable by the mangers. Table 3 makes a pairwise comparisons. 
Table 2. Ranking of FCFS, SPT, EDD, CR and S rules Based on percent Averages

\begin{tabular}{|l|l|l|l|l|l|l|}
\hline & FCFS & SPT & EDD & CR & S & Averages \\
\hline FCFS & .186 & .127 & .405 & .294 & .321 & .267 \\
\hline SPT & .640 & .437 & .293 & .319 & .365 & .411 \\
\hline EDD & .064 & .207 & .139 & .147 & .161 & .144 \\
\hline CR & .049 & .105 & .073 & .077 & .049 & .071 \\
\hline S & .060 & .124 & .089 & .162 & .104 & .108 \\
\hline TOTAL & 1 & 1 & 1 & 1 & 1 & 1 \\
\hline
\end{tabular}

Table 3. Pairwise Comparison of FT, LT and MS rules Based on Average Responses

\begin{tabular}{|l|l|l|l|}
\hline & FT & LT & MS \\
\hline FT & 1 & 3.3 & 4.15 \\
\hline LT & $1 / 3.3$ & 1 & 2.80 \\
\hline MS & $1 / 4.15$ & $1 / 2.80$ & 1 \\
\hline
\end{tabular}

Table 4 represents the ranking of the three rules. Based on percent average, flow time which measure the total waiting and processing time of a job, is the most preferable rules.

Table 4. Ranking of FT, LT and MS rules Based on Average Responses

\begin{tabular}{|l|l|l|l|l|}
\hline & FT & LT & MS & \%Average \\
\hline FT & .648 & .709 & .522 & .626 \\
\hline LT & .196 & .215 & .352 & .254 \\
\hline MS & .156 & .077 & .126 & .120 \\
\hline TOTAL & 1 & 1 & 1 & \\
\hline
\end{tabular}

In this paper, we consider the Shortest Processing Time (SPT) rule for sequencing $\mathrm{N}$ jobs in one facility and we use flow time as a measure of performance. The study is deterministic in nature and assumes demand is forecasted period by period over the finite planning horizon of ten periods. The forecasted demands are scattered according to Increasing, Decreasing, Concave, Convex, Seasonal, and Random patterns represented by I, D, A, V, S, and R respectively in Table 5. Also, each of the demand patterns is scattered with different slopes or coefficients of variations represented by Low (L), Medium (M), and High $(\mathrm{H})$. 
Table 5. The Original Demand Pattern

\begin{tabular}{|c|c|c|c|c|c|c|c|c|c|c|c|}
\hline \multicolumn{2}{|c|}{ Period } & 1 & 2 & 3 & 4 & 5 & 6 & 7 & 8 & 9 & 10 \\
\hline \multirow{3}{*}{ I } & $\mathrm{L}$ & 82 & 86 & 90 & 94 & 98 & 102 & 106 & 110 & 114 & 118 \\
\hline & M & 55 & 65 & 75 & 85 & 95 & 105 & 115 & 125 & 135 & 145 \\
\hline & $\mathrm{H}$ & 1 & & 45 & 67 & 89 & & 133 & 155 & 177 & 199 \\
\hline \multirow{3}{*}{ D } & $\mathrm{L}$ & & & 110 & & 102 & 90 & 94 & 90 & 86 & 82 \\
\hline & $\mathrm{M}$ & 145 & 135 & 125 & 115 & 105 & 95 & 85 & 75 & 65 & 55 \\
\hline & $\mathrm{H}$ & 199 & 177 & 155 & 133 & 111 & 89 & 67 & 45 & 23 & 1 \\
\hline \multirow{3}{*}{$\mathbf{A}$} & $\mathrm{L}$ & 82 & 90 & 98 & 106 & 114 & 118 & 110 & 102 & 94 & 86 \\
\hline & M & 55 & 75 & 95 & 115 & 135 & 145 & 125 & 105 & 85 & 65 \\
\hline & $\mathrm{H}$ & 1 & 45 & 89 & 133 & 177 & 199 & 155 & 111 & 67 & 23 \\
\hline \multirow{3}{*}{ V } & $\mathrm{L}$ & 118 & 110 & 102 & 94 & 86 & 82 & 90 & 98 & 106 & 114 \\
\hline & M & 145 & 125 & 105 & 85 & 65 & 55 & 75 & 95 & 115 & 135 \\
\hline & $\mathrm{H}$ & 199 & & 111 & 67 & 23 & 1 & 45 & 89 & 133 & 177 \\
\hline \multirow{3}{*}{$\mathbf{S}$} & $\mathrm{L}$ & 102 & 110 & 118 & 114 & 106 & 98 & 90 & 82 & 86 & 94 \\
\hline & $\mathrm{M}$ & 105 & 125 & 145 & & 115 & 95 & 75 & 55 & 65 & 85 \\
\hline & $\mathrm{H}$ & 111 & & 199 & 177 & 133 & 89 & 45 & 1 & 23 & 67 \\
\hline \multirow{3}{*}{$\mathbf{R}$} & $\mathrm{L}$ & 90 & & 114 & 82 & 94 & 98 & 118 & 110 & 106 & 86 \\
\hline & M & 75 & 105 & 135 & 55 & 85 & 95 & & & 115 & 65 \\
\hline & $\mathrm{H}$ & 45 & 111 & 177 & 1 & 67 & 89 & 199 & 155 & 133 & 23 \\
\hline
\end{tabular}

The total demand for each demand pattern is set to be equal to 1000 . This constraint is purposely introduced in order to enhance numerical comparability. To generalize the result of this study, the demand for each period is normalized by the ratio of $d_{i} / D$ where $d_{i}$ is the forecasted demand for period $\mathrm{i}$ of each job and $\mathrm{D}=1000$ is the total demand for each pattern over the planning horizon of ten periods. After normalization, Table 6 was obtained. Integrating in the design, all the following variables of demand pattern, cost ratio, coefficients of variation, and PPA lot-sizing rule $(6 * 3 * 3 * 1)$ will produce 54 different solutions. The jobs in this study are represented by their demand pattern. If there are $\mathrm{N}$ jobs to be sequenced in a facility, the $\mathrm{N}$ jobs can be classified and separated according to their forecasted demand pattern. Six jobs are considered in this study. 
Table 6. The Normalized Demand Pattern

\begin{tabular}{|l|l|l|l|l|l|l|l|l|l|l|l|}
\hline \multicolumn{2}{|l}{ Period } & $\mathbf{1}$ & $\mathbf{2}$ & $\mathbf{3}$ & $\mathbf{4}$ & $\mathbf{5}$ & $\mathbf{6}$ & $\mathbf{7}$ & $\mathbf{8}$ & $\mathbf{9}$ & $\mathbf{1 0}$ \\
\hline \multirow{4}{*}{$\mathbf{I}$} & $\mathrm{L}$ & .082 & .086 & .090 & .094 & .098 & .102 & .106 & .110 & .114 & .118 \\
\cline { 2 - 12 } & $\mathrm{M}$ & .055 & .065 & .075 & .085 & .095 & .105 & .115 & .125 & 135 & .145 \\
\cline { 2 - 12 } & $\mathrm{H}$ & .001 & .023 & .045 & .067 & .089 & .111 & .133 & .155 & 177 & .199 \\
\hline \hline \multirow{4}{*}{$\mathbf{D}$} & $\mathrm{L}$ & .118 & .114 & .110 & .106 & .102 & .098 & .094 & .090 & 86 & .082 \\
\cline { 2 - 12 } & $\mathrm{M}$ & .145 & .135 & .125 & .115 & .105 & .095 & .085 & .075 & 65 & .055 \\
\cline { 2 - 12 } & $\mathrm{H}$ & .199 & .177 & .155 & .133 & .111 & .089 & .067 & .045 & 23 & .001 \\
\hline \hline \multirow{4}{*}{$\mathbf{A}$} & $\mathrm{L}$ & .082 & .090 & .098 & .106 & .114 & .118 & .110 & .102 & 94 & .086 \\
\cline { 2 - 11 } & $\mathrm{M}$ & .055 & .075 & .095 & .115 & .135 & .145 & .125 & .105 & 85 & .065 \\
\cline { 2 - 11 } & $\mathrm{H}$ & .001 & .045 & .089 & .133 & .177 & .199 & .155 & .111 & 67 & .023 \\
\hline \hline \multirow{4}{*}{$\mathbf{V}$} & $\mathrm{L}$ & .118 & .110 & .102 & .094 & .086 & .082 & .90 & .098 & 106 & .114 \\
\cline { 2 - 11 } & $\mathrm{M}$ & .145 & .125 & .105 & .085 & .065 & .055 & .075 & .095 & 115 & .135 \\
\cline { 2 - 11 } & $\mathrm{H}$ & .199 & .155 & .111 & .067 & .023 & .001 & .045 & .089 & 133 & .177 \\
\hline \hline \multirow{5}{*}{$\mathbf{S}$} & $\mathrm{L}$ & .102 & .110 & .118 & .114 & .106 & .098 & .090 & .082 & 86 & .094 \\
\cline { 2 - 11 } & $\mathrm{M}$ & .105 & .125 & .145 & .135 & .115 & .095 & .075 & .055 & 65 & .085 \\
\cline { 2 - 11 } & $\mathrm{H}$ & .111 & .155 & .199 & .177 & .133 & .089 & .045 & .001 & 23 & .067 \\
\hline \hline \multirow{5}{*}{$\mathbf{R}$} & $\mathrm{L}$ & .090 & .102 & .114 & .082 & .094 & .098 & .118 & .110 & 106 & .086 \\
\cline { 2 - 10 } & $\mathrm{M}$ & .075 & .105 & .135 & .055 & .085 & .095 & .145 & .125 & 115 & .065 \\
\cline { 2 - 10 } & $\mathrm{H}$ & .045 & .111 & .177 & .001 & .067 & .089 & .199 & .155 & 133 & .023 \\
\hline
\end{tabular}

For example, optimal order quantities can be calculated for the PPA, high cost ratio, high coefficient of variation, with any of the six demand pattern (jobs). To obtain a common cycle of production, an adjustment rule is used as follow: consider three jobs A, B, and C, where optimal order quantity is placed for different periods. Figure 1 represents the above situation.

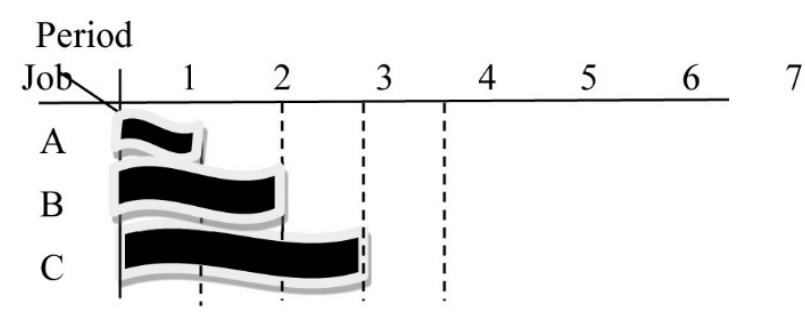

Figure 1. Order Quantity for Jobs A, B, and C

Job A places an order quantity to satisfy the demand for one period, job B places an order quantity to carry over two periods and job $\mathrm{C}$ places an order quantity to carry over three periods.

Period 

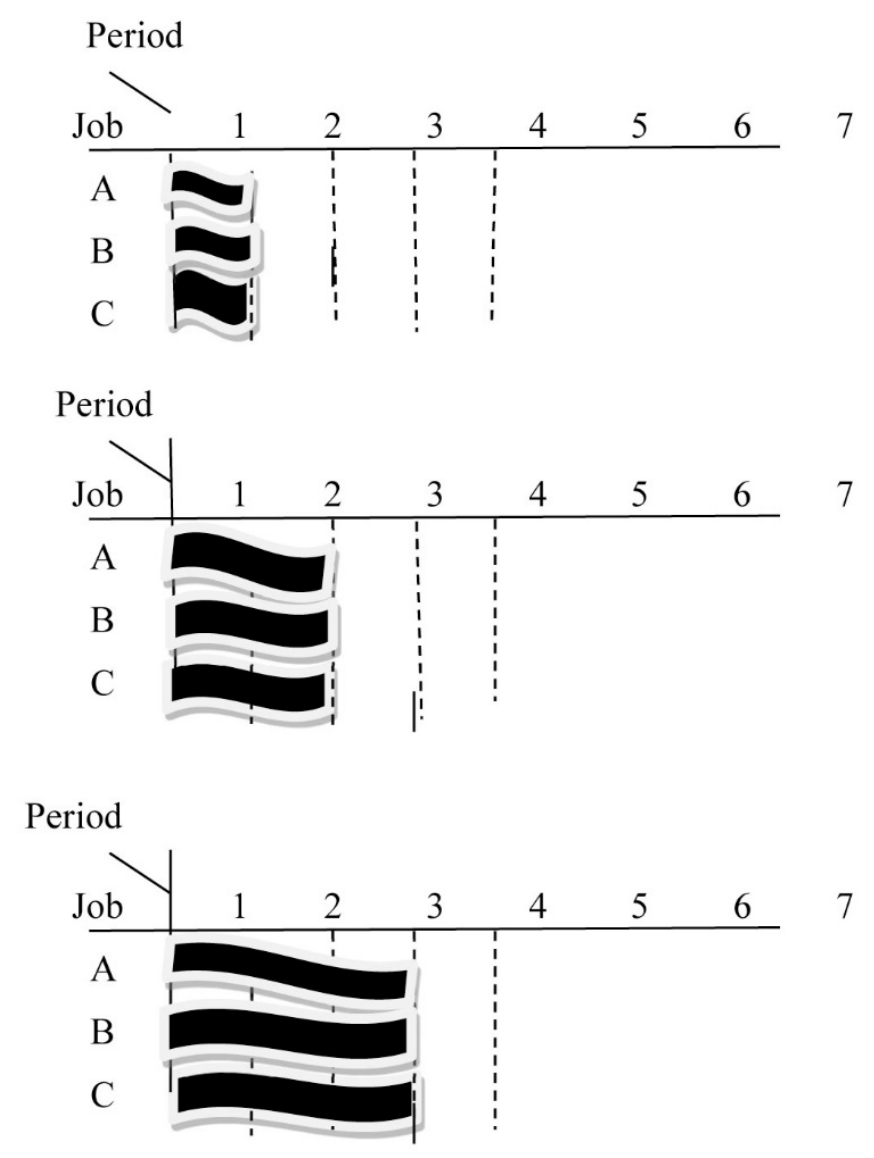

Figure 2. Order Quantity Adjustment for Jobs A, B, and C

In order to form common cycle of production, total cost will be calculated as though all three jobs carry the demand over the total number of periods under consideration. It will be done for one period, two periods, and finally for three periods. The total costs will be compared and the planning horizon which results in the least total cost becomes the cycle of production. This method will be continued for the calculation of the next cycle of production. The cycles of production may or may not be the same. Figure 2 represents this situation.

\section{Results}

A program has been developed to analyze the four-way interaction of the following variables, demand pattern, cost ratio, coefficients of variation, and PPA lot-sizing rule. For example, order quantities can be calculated for the PPA Algorithm, high cost ratio, high coefficient of variation, with six demand patterns (jobs). The result is presented in Table 7 . 
Table 7. The Order Quantity Without Cycles of Production Adjustment

\begin{tabular}{|l|l|l|l|l|l|l|l|l|l|l|}
\hline Period & $\mathbf{1}$ & $\mathbf{2}$ & $\mathbf{3}$ & $\mathbf{4}$ & $\mathbf{5}$ & $\mathbf{6}$ & $\mathbf{7}$ & $\mathbf{8}$ & $\mathbf{9}$ & $\mathbf{1 0}$ \\
\hline I & 69 & & & 156 & & 244 & & 155 & 177 & 199 \\
\hline D & 199 & 177 & 288 & & 200 & & 136 & & & \\
\hline A & 135 & & & 133 & 177 & 199 & 266 & & 90 & \\
\hline V & 199 & 266 & & 136 & & & & 222 & & 177 \\
\hline S & 266 & & 199 & 310 & & 158 & & & & 67 \\
\hline R & 156 & & 245 & & & 89 & 199 & 288 & & 23 \\
\hline
\end{tabular}

orders for each job. As can be observed, all the jobs enter the work center at different time periods. The order quantities represent different reentrance period for each job. For example, job I places an order of size 69, 156, 244, 155, 177, and 199 in periods 1, 4, 6, 8, 9 , and 10 respectively; job D places an order of size 199, 177, 288, 200, and 136 in periods $1,2,3,5$, and 7 respectively. A uniform cycle of production time is the time in which an order of size $\mathrm{Q}_{\mathrm{i}}$, for $\mathrm{i}=1$ to 6 jobs, will cover a fixed number of planning horizon. To obtain a uniform cycle of production, the following adjustment is made. The first cycle of production starts at period 1 . The decision to be made is how much of each job should be produced so that all the jobs reenter the work center simultaneously. In PPA, the decision as to when and how much to produce is based on comparison of EPP (Economic Part Period) to CPP (Cumulative Part Period). The incremental part period (IPP) is defined as the number of parts held in inventory multiplied by the number of periods over which they are held. The cumulative part period (CPP) is the summation of IPP over the time. The Economic Part Period (EPP) is the number of periods it takes to make order cost and holding cost equal. The EPP can be obtained by dividing order cost by inventory holding cost per part, per period. Hence, the decision as to when and how much to order is obtained by comparing CPP to EPP. When the CPP value is first greater than the EPP value an order should be released. The order quantity $\mathrm{Q}$ will be the accumulated demand up to the time for the next order $(\mathrm{CPP}<\mathrm{EPP})$.

The same decision criteria will be used for development of the cycles of production for PPA, where demand for each period will be the sum of demands for all the jobs over that period. For example, the total demand in period 1 for jobs I, D, A, V, S, and R, for high $(\mathrm{H})$ CVs would be:

$$
1+199+1+199+111+45=556
$$

Therefore, the demand for each period, for all the jobs, would be:

\begin{tabular}{|l|l|l|l|l|l|l|l|l|l|l|}
\hline Period & $\mathbf{1}$ & $\mathbf{2}$ & $\mathbf{3}$ & $\mathbf{4}$ & $\mathbf{5}$ & $\mathbf{6}$ & $\mathbf{7}$ & $\mathbf{8}$ & $\mathbf{9}$ & $\mathbf{1 0}$ \\
\hline Demand & 556 & 666 & 776 & 578 & 600 & 578 & 644 & 556 & 556 & 490 \\
\hline
\end{tabular}

The ordering cost for six different jobs would be the sum of ordering costs for all the jobs over that period. The ordering cost for each cycle of production would be $\mathrm{C}_{\mathrm{O}}=6(300)=$ 1800. Therefore, $\mathrm{EPP}=1800$. The cycles of production will be formed where carrying over 
a given period is not more economical than ordering in that period (CPP $>$ EPP).

\begin{tabular}{|l|l|l|l|l|}
\hline Period & Demand & Q & IPP & CPP \\
\hline $\mathbf{1}$ & 556 & 556 & 278 & 388 \\
\hline $\mathbf{2}$ & 666 & 1222 & $666(1+5)=999$ & 1277 \\
\hline $\mathbf{3}$ & 776 & 1998 & $776(2+5)=1940$ & $321>$ EPP $=1800$ \\
\hline
\end{tabular}

The first cycle of production is formed in period 1 and produces enough to satisfy the demand for periods 1 and 2. All the jobs reenter the work center in period 3. To decide how many periods will be covered in the second cycle of production, the following analysis will be performed:

\begin{tabular}{|l|l|l|l|l|}
\hline Period & Demand & Q & IPP & CPP \\
\hline $\mathbf{1}$ & 776 & 776 & 388 & 388 \\
\hline $\mathbf{2}$ & 578 & 1354 & $578(1+5)=867$ & 1255 \\
\hline $\mathbf{3}$ & 600 & 1954 & $600(2+5)=1500$ & $2755>\mathrm{EPP}=1800$ \\
\hline
\end{tabular}

Therefore, the second cycle of production starts in period 3 and produces enough to satisfy the demand for periods 3 and 4 . The above procedure continues for the successive periods and finally the following table will be obtained.

Table 8. The Order Quantities with Cycles of Production Adjustment

\begin{tabular}{|l|l|l|l|l|l|l|l|l|l|l|}
\hline Period & $\mathbf{1}$ & $\mathbf{2}$ & $\mathbf{3}$ & $\mathbf{4}$ & $\mathbf{5}$ & $\mathbf{6}$ & $\mathbf{7}$ & $\mathbf{8}$ & $\mathbf{9}$ & $\mathbf{1 0}$ \\
\hline I & 24 & & 112 & & 200 & & 288 & & 376 & \\
\hline D & 376 & & 288 & & 200 & & 112 & & 24 & \\
\hline A & 46 & & 222 & & 376 & & 266 & & 90 & \\
\hline V & 354 & & 178 & & 24 & & 134 & & 310 & \\
\hline S & 266 & & 376 & & 222 & & 46 & & 90 & \\
\hline R & 156 & & 178 & & 156 & & 354 & & 156 & \\
\hline
\end{tabular}

The above table indicates the order quantities for each job at the beginning of each cycle. In order to generalize the results, tables are developed in the form of normalized data variables. It can be easily demonstrated that the normalized data will have the same result as the original data.

Table 9. The Final Normalized Result

\begin{tabular}{|l|l|l|l|l|l|l|l|l|l|l|}
\hline Period & $\mathbf{1}$ & $\mathbf{2}$ & $\mathbf{3}$ & $\mathbf{4}$ & $\mathbf{5}$ & $\mathbf{6}$ & $\mathbf{7}$ & $\mathbf{8}$ & $\mathbf{9}$ & $\mathbf{1 0}$ \\
\hline $\mathbf{I}$ & $.024^{\mathrm{a}}$ & & $.112^{\mathrm{a}}$ & & $.200^{\mathrm{d}}$ & & $.288^{\mathrm{e}}$ & & $.376^{\mathrm{f}}$ & \\
\hline D & $.376^{\mathrm{f}}$ & & $.288^{\mathrm{e}}$ & & $.200^{\mathrm{c}}$ & & $.112^{\mathrm{b}}$ & & $.024^{\mathrm{a}}$ & \\
\hline A & $.046^{\mathrm{b}}$ & & $.222^{\mathrm{d}}$ & & $.376^{\mathrm{f}}$ & & $.266^{\mathrm{d}}$ & & $.090^{\mathrm{b}}$ & \\
\hline V & $.354^{\mathrm{e}}$ & & $.178^{\mathrm{b}}$ & & $.024^{\mathrm{a}}$ & & $.134^{\mathrm{c}}$ & & $.310^{\mathrm{e}}$ & \\
\hline S & $.266^{\mathrm{d}}$ & & $.376^{\mathrm{f}}$ & & $.222^{\mathrm{e}}$ & & $.046^{\mathrm{a}}$ & & $.090^{\mathrm{c}}$ & \\
\hline R & $.156^{\mathrm{c}}$ & & $.178^{\mathrm{c}}$ & & $.156^{\mathrm{b}}$ & & $.354^{\mathrm{f}}$ & & $.156^{\mathrm{d}}$ & \\
\hline
\end{tabular}




\section{Macrothink $\Lambda$ Institute"}

The generalization is made for the series of demand patterns with the same slope or coefficient of variations used in this study. For other cases, the same methodology can be used to develop tables to suit specific situations. The final normalized result is shown in Table 9.

The superscripts $\mathrm{a}, \mathrm{b}, \mathrm{c}, \mathrm{d}$, e, and $\mathrm{f}$ are used for the jobs in each cycle to represent the sequence in which the jobs should enter the work center. The order is based on the Shortest Processing Time (SPT) sequencing rule. Table 5 represents the final normalized result of the above example. Since the developed tables are based on the normalized quantities, for determination of the exact order quantities, normalized order quantities should be transformed to original order quantities should. The transformation from the normalized order quantity to original order quantity would be:

$$
\text { Order Quantity }=(\# \text { in a cell })(\text { total demand })(\mathrm{K} / \text { average demand })
$$

Therefore, for the above example;

$$
\text { Order Quantity }=(\# \text { in a cell })(1000)(\mathrm{K} / 100)
$$

where $\mathrm{K}$ is the average demand parallel to any of the demand patterns examined in this study.

The average demand used for the demand patterns in this study is 100 . Therefore, $(\mathrm{K} / 100)$ is the magnitude or the ratio of any of the lines parallel to the demand pattern under consideration. The numbers in the cells are normalized by the total demand of 1000 over the planning horizon of 10 periods. Hence, the product of (\# in a cell)(1000)(K/100) results in the original order quantity for any scale or magnitude within the class of lines parallel to the examined demand pattern.

For example, consider the demand with the forecasted demand quantity that is five times as high as the demand used in our study $(\mathrm{K}=500)$. The order quantities will be obtained by utilizing formula (1) in Table 5. The normalized result in Table 10, which indicates timing, quantity, sequencing, and production cycles are obtained.

Table 10. The Final Normalized Result

\begin{tabular}{|l|l|l|l|l|l|l|l|l|l|l|}
\hline Period & $\mathbf{1}$ & $\mathbf{2}$ & $\mathbf{3}$ & $\mathbf{4}$ & $\mathbf{5}$ & $\mathbf{6}$ & $\mathbf{7}$ & $\mathbf{8}$ & $\mathbf{9}$ & $\mathbf{1 0}$ \\
\hline I & $120^{\mathrm{a}}$ & & $560^{\mathrm{a}}$ & & $1000^{\mathrm{d}}$ & & $1440^{\mathrm{e}}$ & & $1880^{\mathrm{f}}$ & \\
\hline D & $1880^{\mathrm{f}}$ & & $1440^{\mathrm{e}}$ & & $1000^{\mathrm{c}}$ & & $560^{\mathrm{b}}$ & & $120^{\mathrm{a}}$ & \\
\hline A & $230^{\mathrm{b}}$ & & $1110^{\mathrm{d}}$ & & $1880^{\mathrm{f}}$ & & $1330^{\mathrm{d}}$ & & $450^{\mathrm{b}}$ & \\
\hline V & $1770^{\mathrm{e}}$ & & $890^{\mathrm{b}}$ & & $120^{\mathrm{a}}$ & & $670^{\mathrm{c}}$ & & $1550^{\mathrm{e}}$ & \\
\hline S & $1330^{\mathrm{d}}$ & & $1880^{\mathrm{f}}$ & & $1110^{\mathrm{e}}$ & & $230^{\mathrm{a}}$ & & $450^{\mathrm{c}}$ & \\
\hline R & $780^{\mathrm{c}}$ & & $890^{\mathrm{c}}$ & & $780^{\mathrm{b}}$ & & $1770^{\mathrm{f}}$ & & $780^{\mathrm{d}}$ & \\
\hline
\end{tabular}




\section{Impact on cost}

The total cost before and after the cycles of production adjustment for each situation is recorded for the three costs ratio of: Low $=0.75$, Medium $=1.50$, and High $=3.00$. Three levels of cost ratios represented as Low (L), Medium (M), and High (H), and three coefficients of variation (slope) are used. The comparison of costs reveals that the magnitude of total cost has changed in most cases when forming cycles of productions. In some cases, it has increased and in some cases it decreased. This result was expected since PPA is not an optimization technique. However, by forming cycles of production for a group of jobs in a period, the work center is utilized for that group in that period only. During other periods where the cycle is not formed, labor could be scheduled for other tasks in the work center and machines could be scheduled to perform other jobs, thus utilizing the work center for other tasks and activities. This will result in reducing employee and machine idleness, and work center utilization would go up.

Table 11. Total Cost Comparison for Before and after the Cycles of Production Adjustment

\begin{tabular}{|l|l|l|l|}
\hline \multicolumn{2}{|l|}{$\begin{array}{l}\text { Cost } \\
\text { Ratio }\end{array}$} & $\begin{array}{l}\text { Before } \\
\text { Cycles }\end{array}$ & $\begin{array}{l}\text { After } \\
\text { Cycles }\end{array}$ \\
\hline \multirow{3}{*}{3.00} & $\mathrm{H}$ & 15095 & 14868 \\
\cline { 2 - 4 } & $\mathrm{M}$ & 14985 & 14940 \\
\cline { 2 - 4 } & $\mathrm{L}$ & 14976 & 14976 \\
\hline \hline \multirow{3}{*}{1.50} & $\mathrm{H}$ & 10336 & 12000 \\
\cline { 2 - 4 } & $\mathrm{M}$ & 11320 & 12000 \\
\cline { 2 - 4 } & $\mathrm{L}$ & 12000 & 12000 \\
\hline \hline \multirow{3}{*}{0.75} & $\mathrm{H}$ & 7042 & 7500 \\
\cline { 2 - 4 } & $\mathrm{M}$ & 7500 & 7500 \\
\cline { 2 - 4 } & $\mathrm{L}$ & 7500 & 7500 \\
\hline \hline
\end{tabular}

\section{Conclusion}

The integration of AHP with scheduling, sequencing, and uniform production cycle in multi-product production facilities has been introduced and discussed in this paper. Also, the concept of uniform cycles of production time was introduced. A methodology to develop tables, for the Part Period Algorithm (PPA) rule to account for the effect of uniform production cycles has been demonstrated. Based on the results of each case, appropriate tables were developed to assist production managers in making decisions concerning order quantity of jobs at the beginning of each cycle, the timing of orders for each job, and the processing sequence of jobs. Once the tables are developed, a production manager can properly schedule tasks in the work center to minimize waste of both employee and machine times. Savings in employee time could be used for other tasks in the work center and savings in machine time could be used to perform other jobs.

\section{References}

Baciarello, L., D’Avino, M., \& Onori, R. Schiraldi, M. (2013). Lot Sizing Heuristics 
Performance. International Journal of Engineering Business Management, 5, 1-10. https://doi.org/10.5772/56004

Bahl, HC, Ritzman, LP, \& Gupta, JND. (1987). Determining lot sizes and resources requirements: A review. Operations Research, 35(3), 329-345. https://doi.org/10.1287/opre.35.3.329

Berry, W.L. (1972). Lot Sizing Procedures for Requirements Planning Systems: A Framework For Analysis. Production and inventory Management, 13(2), 19-34.

Brahimi, N, Dauzere-Peres, S, Najid, NM, \& Nordli, A (2006) Single item lot sizing problems. European Journal of Operations Research, 168, 1-16. https://doi.org/10.1016/j.ejor.2004.01.054

Buschkühl, L, Sahling, F, Helber, S, \& Tempelmeier, H. (2010). Dynamic capacitated lot-sizing problems: A classification and review of solution approaches. OR Spectrum, 32(2), 231-261. https://doi.org/10.1007/s00291-008-0150-7

Clark, A.R. (2003). Hybird Heuristics for Planning Lot Steps and Sizes. Computers \&Industrial Engineering, 45, 545-562. https://doi.org/10.1016/S0360-8352(03)00073-1

Collier, D.A. (1980). The Interaction of Single Stage Lot Size Models in Material Requirement Planning Environment. Production and Inventory Management, 21(4), 11-20.

Davis, E.W. (1975). A Look at Use of Production Inventory Techniques: Past and Present. Production and Inventory Management, 16(3), 471-478.

Denny, T. U., Gumilang, M. A., \& Purnomo, B. S. (2021). Database design with product structure, bill of material and group technology for supplier decision support systems (0RW1S34RfeSDcfkexd09rT2case study: Hand tractor manufacturing1RW1S34RfeSDcfkexd09rT2). IOP Conference Series. Materials Science and Engineering, 1034(1).

Doll, C.L., \& D. C. Whybark. (1973). An Iterative Procedure for the Single-Machine Multi Product Lot Scheduling Problem. Management Science, 20(1). https://doi.org/10.1287/mnsc.20.1.50

Gelders, L.F., Maes, J., \& Van Wassenhove, L.N. (1986). A Branch and Bound Algorithm for the Multiple Item Single Level Capacitated Dynamic Lot-Sizing Problem. Economics

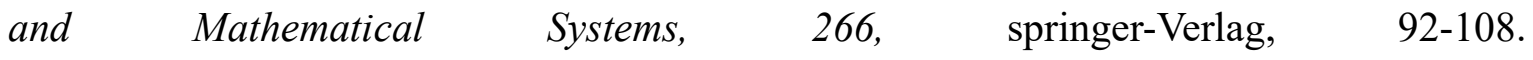
https://doi.org/10.1007/978-3-642-51693-1_5

Gopalakrishnan, M., Ding, K., Bourjolly, J., \& Mohan, S. (2001). A Tabu-Search Heurestic for the Capacitated Lot-Sizing Problem with St-up Carryover. Management Science. $47,851-863$.

Goren, HC, Tunali, S, \& Jans, R. (2010). A review of applications of genetic algorithms in lot sizing. Journal of Intelligent Manufacturing, 21(4), 575-590. https://doi.org/10.1007/s10845-008-0205-2 
Goyal, S.K. (1973). Scheduling a Multi-Product Single-Machine System. Operations Research Quarterly, 24(2). https://doi.org/10.1057/jors.1973.43

Haessler, R. (1971). A Note on Scheduling a Multi-Product Single Machine System for an Infinite Planning Period. Management Science, 18(4). https://doi.org/10.1287/mnsc.18.4.B240

, R., \& S. Hogue. (1976). A Note on the Single-Machine Multi-Product Lot Scheduling Problem Management Science, 22(8). https://doi.org/10.1287/mnsc. 18.4.B240

Haddock, J, \& Hubicky, D. E. (1989). Which lot sizing techniques are used in Materials Requirements Planning? Production and Inventory Management, 30(3), 53-56.

Han, Y, Cai, J, Kaku, Y, Li, Y, Chen, Y, \& Tang, J (2012) Evolutionary algorithms for solving unconstrained multilevel lot-sizing problem with series structure. Journal of Shanghai Jiaotong University-Science, $\quad 17(1), \quad 39-44$. https://doi.org/10.1007/s12204-012-1227-7

Hodson, T.J. (1970). Scheduling a Multi-Product Single-Machine System for an Infinite Planning Period. Management Science, 16(7). https://doi.org/10.1287/mnsc.14.11.713

Kaiman, R.A. (1969). EOQ vs. Dynamic Programming: Which One to Use for Inventory Ordering. Production and Inventory Management, 4.

Karni, R., \& Y. Roll. (1982). A heuristic Algorithm for the Multi Item Lot Sizing Problem with Capacity Constraints. IIE Transactions, 14(4), 149-156. https://doi.org/10.1080/05695558208975237

Madigan, F.G. (1968). Scheduling a Multi-Product Single Machine System for an Infinite Planning Period. Management Science, 14(11). https://doi.org/10.1287/mnsc.14.11.713

Miller, I., \& J. E. Freund. (1985). Probability and Statistics for Engineers, Third Edition. Prentice Hall.

Meyer, H. (2000). Simultaneous Lot-Sizing and Scheduling by combining Local Search With Dual Reoptimization. European Journal of Operational Research, 120, 311-326.

Parcom, P. (2007). Developing your decision making skills. New Delhi, India: Lotus Press.

Power, Daniel J. (2021). Glossary of key decision support systems terms. Decision Support Systems Resources. https://www.dssresources.com/

Pujawan, N., \& Kingsman, B. (2003). Properties of lot-sizing Rules Under Lumpy Demand. International Journal of Production Economics, 81-82, 295-307. https://doi.org/10.1016/S0925-5273(02)00363-8

Satty, L. T. (1980). The Analytical Hierarchy Process, Mc Graw Hill Company, New York. Suerie, C., \& Stadtler, H., (2003). The capacitated Lot-Sizing Problem with linked lot Sizes. Management $\quad$ Science, $1039-1054$. https://doi.org/10.1287/mnsc.49.8.1039.16406 
Stevenson, J.W. (2018). Operations Management, thirteen editions. McGraw Hill.

Tiacci, L, Saetta, S (2012) Demand forecasting, lot sizing and scheduling on a rolling horizon basis. International Journal of Production Economics, 140(2), 803-814. https://doi.org/10.1016/j.ijpe.2012.02.007

Van den Heuvel, W, \& Wagelmans, APM (2010) Worst-Case Analysis for a General Class of Online Lot-Sizing Heuristics. Operations Research, 58(1), 59-67. https://doi.org/10.1287/opre.1080.0662

Veral, E.V., \& R. L. LaForge. (1985). The performance of a Simple Incremental Lot Sizing Rule in Multi-Level Inventory Environment. Decision Sciences, 16, 57-72. https://doi.org/10.1111/j.1540-5915.1985.tb01475.x

Winands, EMM, Adan, IJBF, \& van Houtum, GJ (2011) The stochastic economic lot scheduling problem: A survey. European Journal of Operational Research, 210(1), 1-9. https://doi.org/10.1016/j.ejor.2010.06.011

Wagner, H.M., \& Whitin. (1958). Dynamic Version of the Economic Lot Size Model. Management Science, 5, 89-96. https://doi.org/10.1287/mnsc.5.1.89

Xiao, Y, Kaku, Y, Zhao, Q, \& Zhang, R. (2012) Neighborhood search techniques for solving uncapacitated multilevel lot-sizing problems. Computers \& Operations Research, 9, 6478. https://doi.org/10.1016/j.cor.2011.06.004 